\title{
Mitral valve repair or replacement for ischemic mitral regurgitation? The Italian Study on the Treatment of Ischemic Mitral Regurgitation (ISTIMIR)
}

\author{
Roberto Lorusso, MD, PhD, ${ }^{\mathrm{a}}$ Sandro Gelsomino, MD, PhD, ${ }^{\mathrm{b}}$ Enrico Vizzardi, MD, ${ }^{\mathrm{a}}$ Antonio D' Aloia, MD, ${ }^{\mathrm{a}}$ \\ Giuseppe De Cicco, MD, ${ }^{\mathrm{a}}$ Fabiana Lucà, MD, ${ }^{\mathrm{b}}$ Orlando Parise, MSc, ${ }^{\mathrm{b}}$ Gian Franco Gensini, MD, \\ Pierluigi Stefàno, MD, ${ }^{\mathrm{b}}$ Ugolino Livi, MD,${ }^{\mathrm{c}}$ Igor Vendramin, $\mathrm{MD},{ }^{\mathrm{c}}$ Davide Pacini, MD,${ }^{\mathrm{d}}$ \\ Roberto Di Bartolomeo, MD, ${ }^{\mathrm{d}}$ Antonio Miceli, MD, PhD, ${ }^{\mathrm{e}}$ Egidio Varone, MD, ${ }^{\mathrm{e}}$ Mattia Glauber, MD, \\ Alessandro Parolari, MD,${ }^{\mathrm{f}}$ Francesco Giuseppe Arlati, MD, ${ }^{\mathrm{f}}$ Francesco Alamanni, MD, ${ }^{\mathrm{f}}$ \\ Filiberto Serraino, MD, ${ }^{\mathrm{g}}$ Attilio Renzulli, MD, ${ }^{\mathrm{g}}$ Antonio Messina, MD, PhD, ${ }^{\mathrm{h}}$ Giovanni Troise, MD, \\ Giovanni Mariscalco, MD, PhD, ${ }^{\mathrm{i}}$ Marzia Cottini, MD, ${ }^{\mathrm{i}}$ Cesare Beghi, MD, ${ }^{\mathrm{i}}$ Francesco Nicolini, MD, PhD, ${ }^{\mathrm{j}}$ \\ Tiziano Gherli, MD, ${ }^{\mathrm{j}}$ Valentino Borghetti, MD ${ }^{\mathrm{k}}$ Alessandro Pardini, MD, ${ }^{\mathrm{k}}$ Philippe-Primo Caimmi, MD, ${ }^{1}$ \\ Ezio Micalizzi, MD, ${ }^{\mathrm{l}}$ Carlo Fino, MD, ${ }^{\mathrm{m}}$ Paolo Ferrazzi, MD, ${ }^{\mathrm{m}}$ Michele Di Mauro, MD,${ }^{\mathrm{n}}$ and \\ Antonio Maria Calafiore, MD, ${ }^{\mathrm{n}}$ the ISTIMIR Investigators
}

Objective: It is uncertain whether mitral valve replacement is really inferior to mitral valve repair for the treatment of chronic ischemic mitral regurgitation. This multicenter study aimed at providing a contribution to this issue.

\begin{abstract}
Methods: Of 1006 patients with chronic ischemic mitral regurgitation and impaired left ventricular function (ejection fraction $<40 \%$ ) operated on at 13 Italian institutions between 1996 and 2011, 298 (29.6\%) underwent mitral valve replacement whereas $708(70.4 \%)$ received mitral valve repair. Propensity scores were calculated by a nonparsimonious multivariable logistic regression, and 244 pairs of patients were matched successfully using calipers of width 0.2 standard deviation of the logit of the propensity scores. The postmatching median standardized difference was 0.024 (range, 0-0.037) and in none of the covariates did it exceed $10 \%$.
\end{abstract}

Results: Early deaths were $3.3 \%(\mathrm{n}=8)$ in mitral valve repair versus $5.3 \%(\mathrm{n}=13)$ in mitral valve replacement $(P=.32)$. Eight-year survival was $81.6 \% \pm 2.8 \%$ and $79.6 \% \pm 4.8 \%(P=.42)$, respectively. Actual freedom from all-cause reoperation and valve-related reoperation were $64.3 \% \pm 4.3 \%$ versus $80 \% \pm 4.1 \%$, and $71.3 \%$ $\pm 3.5 \%$ versus $85.5 \% \pm 3.9$ in mitral valve repair and mitral valve replacement, respectively $(P<.001)$. Actual freedom from all valve-related complications was $68.3 \% \pm 3.1 \%$ versus $69.9 \% \pm 3.3 \%$ in mitral valve repair and mitral valve replacement, respectively $(P=.78)$. Left ventricular function did not improved significantly, and it was comparable in the 2 groups postoperatively $(36.9 \%$ vs $38.5 \%, P=.66)$. At competing regression analysis, mitral valve repair was a strong predictor of reoperation (hazard ratio, $2.84 ; P<.001$ ).

Conclusions: Mitral valve replacement is a suitable option for patients with chronic ischemic mitral regurgitation and impaired left ventricular function. It provides better results in terms of freedom from reoperation with comparable valve-related complication rates. (J Thorac Cardiovasc Surg 2013;145:128-39)

Earn CME credits at

http://cme.ctsnetjournals.org
From the Cardiac Surgery Unit, ${ }^{a}$ Community Hospital, Brescia, Italy; Cardiovascular Research and Cardiac Surgery Units, ${ }^{\mathrm{b}}$ Careggi Hospital, Florence, Italy; Cardiac Surgery, ${ }^{c}$ Ospedale S. Maria della Misericordia, Udine, Italy; Cardiac Surgery Unit, ${ }^{\mathrm{d}}$ Ospedale S. Orsola-Malpighi, Bologna, Italy; Cardiac Surgery Unit, ${ }^{\mathrm{e}}$ Ospedale Pasquinucci, Fondazione Manasterio, Massa, Italy; Cardiac Surgery Unit, ${ }^{\mathrm{f}}$ Centro Cardiologico Monzino, Milan, Italy; Cardiac Surgery Unit, ${ }^{\mathrm{g}}$ Ospedale, Catanzaro, Italy; Cardiac Surgery Unit, ${ }^{\mathrm{h}}$ Ospedale Poliambulanza, Brescia, Italy; Cardiac Surgery Unit, ${ }^{\mathrm{i}}$ Ospedale di Circolo, Varese, Italy; Cardiac Surgery Unit ${ }^{j}$ Ospedale Maggiore, Parma, Italy; Cardiac Surgery Unit, ${ }^{\mathrm{k}}$ Ospedale Terni, Terni, Italy; Cardiac Surgery Unit, ${ }^{1}$ Ospedale Novara, Novara, Italy; Cardiac Surgery Unit, ${ }^{\mathrm{m}}$ Spedali Riuniti, Bergamo, Italy; and Cardiac Surgery Unit, ${ }^{\mathrm{n}}$ Ospedale Ferrarotto, Catania, Italy.
Chronic ischemic mitral regurgitation (CIMR) is a frequent complication of myocardial infarction. Its pathophysiologic mechanisms account for segmental/global left ventricular (LV) remodeling leading to papillary muscle displacement

Disclosures: Authors have nothing to disclose with regard to commercial support. Read at the 92nd Annual Meeting of The American Association for Thoracic Surgery, San Francisco, California, April 28-May 2, 2012.

Drs Lorusso and Gelsomino contributed equally to the article.

Received for publication April 15, 2012; revisions received July 19, 2012; accepted for publication Sept 13, 2012; available ahead of print Nov 5, 2012.

Address for reprints: Sandro Gelsomino, MD, PhD, Department of Heart and Vessels, Careggi Hospital, Via Delle Oblate 1, 50134 Florence, Italy (E-mail: sandro. gelsomino@libero.it).

$0022-5223 / \$ 36.00$

Copyright $(\subset) 2013$ by The American Association for Thoracic Surgery http://dx.doi.org/10.1016/j.jtcvs.2012.09.042 


$$
\begin{aligned}
& \text { Abbreviations and Acronyms } \\
& \begin{aligned}
\text { CABG } & =\text { coronary artery bypass grafting } \\
\mathrm{CI} & =\text { confidence interval } \\
\mathrm{CIMR} & =\text { chronic ischemic mitral regurgitation } \\
\mathrm{HR} & =\text { hazard ratio } \\
\mathrm{IQR} & =\text { interquartile range } \\
\mathrm{LV} & =\text { left ventricular } \\
\mathrm{LVEF} & =\text { left ventricular ejection fraction } \\
\mathrm{MR} & =\text { mitral regurgitation } \\
\mathrm{MVP} & =\text { mitral valve plasty } \\
\mathrm{MVR} & =\text { mitral valve replacement } \\
\mathrm{PS} & =\text { propensity score } \\
\mathrm{SVD} & =\text { structural valve degeneration }
\end{aligned}
\end{aligned}
$$

and leaflet tethering in the presence of a structurally normal valve and subvalvular apparatus, with or without annular dilatation. ${ }^{1}$ Left ventricular dysfunction may affect up to $20 \%$ of patients with CIMR, and it carries a poorer prognosis. ${ }^{1,2}$ The optimal management of patients with CIMR remains to be established..$^{2,3-5}$ The benefit of mitral valve plasty (MVP) compared with mitral valve replacement (MVR) has been shown convincingly in patients affected by degenerative mitral regurgitation (MR), but such an advantage remains controversial in the presence of CIMR, ${ }^{2,3-10}$ particularly in case of concurrent LV dysfunction. ${ }^{11,12}$

Published series on long-term results of mitral valve surgery in CIMR patients, however, have also included patients affected by regurgitation secondary to idiopathic cardiomyopathy or to degenerative disease, or by acute regurgitation resulting from papillary muscle rupture, or they have been carried out with limited heterogeneous patient cohorts, making conclusive interpretation unfeasible., ${ }^{2,4-6}$ Therefore, a multicenter, 15-year, retrospective, propensity score (PS)matched analysis of a robust patient cohort was designed to elucidate comparative effectiveness of MVP and MVR in association with coronary artery bypass grafting $(\mathrm{CABG})$ and in the presence of LV dysfunction. Careful patient selection was carried out purposefully to focus on a homogeneous patient population, eliminating some common confounding factors characterizing published series on the matter, and assessing early and long-term postoperative outcomes.

\section{METHODS}

\section{Patient Cohort and Data Collection}

Thirteen Italian centers participated in the study. Data were collected from patient charts for preoperative, operative, and hospital admittance details, and through direct or telephone interview with survivors, with relatives, with general practitioners, or with hospital doctors in the case of patients hospitalized for any cause after surgery. Patients were followed up according to each individual institutional protocol.

Data refer to patients with CIMR and LV ejection fraction (LVEF) $<40 \%$ undergoing CABG procedure associated with MVP with downsizing ring annuloplasty or MVR between 1996 and 2011. Chronic ischemic MR was defined according to the following criteria: (1) prior myocardial infarction $>16$ days, (2) $70 \%$ or greater stenosis of at least 1 coronary vessel, (3) a corresponding regional wall motion abnormality, and (4) type I/IIIb leaflet dysfunction following Carpentier's classification with or without annular dilatation.

There were 1290 patients who met the CIMR definition. From this patient population, 284 subjects were excluded because of emergency surgery, repeat operation, LV reconstruction/reshaping, partial band/pericardial annuloplasty, associated procedures other than ring annuloplasty for MVP, residual MR $\geq 2+$ or paravalvular leak at hospital discharge, or infective endocarditis, congenital valvular heart disease, rheumatic valvular disease, mitral stenosis, or associated valvular heart disease.

The final study cohort included 1006 patients; 708 patients (70.4\%) underwent MVP and $298(29.6 \%)$ underwent MVR. All collected data were sent to a core lab (Cardiovascular Research Unit, Ospedale Careggi, Florence, Italy) for analysis.

Ethical committee approval was waived because of the retrospective analysis of the study according to the national law regulating observational retrospective studies (law nr. 11960, released on July 13, 2004). Median follow-up was 46.5 months (interquartile range [IQR], 26.6-69.0 months) with a total of 1.942 years of evaluation. At the end of the follow-up (July 31, 2011) the completeness of the follow-up was $94.8 \%$. There was no statistically significant difference in median length of follow-up between MVR and MVP $(P=.4)$.The definitions of valve-related complications followed guidelines for reporting morbidity and mortality after cardiac valvular interventions. ${ }^{13}$

The decision to perform repair or replacement was at the surgeon's discretion. Downsizing ring annuloplasty (2 sizes) was used in all patients subjected to MVP. The ring size was determined by standard measurements of the intertrigonal distance and anterior leaflet height. All patients underwent complete revascularization. ${ }^{14}$

A successful repair was defined as a leaflet coaptation of $\geq 0.8 \mathrm{~cm}, \mathrm{MR}$ $\leq 1$, and mitral valve area $>2 \mathrm{~cm}^{2}$ at transesophageal echocardiography performed at the end of cardiopulmonary bypass.

\section{Echocardiography}

Mitral regurgitation was graded following the American Society of Echocardiography recommendations. ${ }^{15}$ Recurrence of MR was defined as postoperative $\mathrm{MR} \geq 2+$. All echocardiographic measurements followed American Society of Echocardiography and European Society of Echocardiography guidelines. ${ }^{16}$

\section{Statistical Analysis}

Estimation of PS and matching. Because of the significant imbalances in baseline covariates between groups, we used PS matching. ${ }^{17} \mathrm{~A}$ PS representing the probability of having MVR as opposed to MVP was calculated for each patient by using a logistic regression model that identified variables associated independently with the type of surgical procedure. Variables used in the model are shown in Tables 1 and 2. Pairs of patients with MVP and MVR were matched using calipers of width 0.2 standard deviations of the logit of the PS. ${ }^{18}$ Covariate balance was measured using the standardized differences, by which an absolute standardized difference $>0.1$ is suggested to represent meaningful covariate imbalance. ${ }^{17}$ We accounted for the referring center by introducing in the PS a categoric variable indicating the center.

Estimating treatment effects. Matched data were compared between MVP and MVR using the Wilcoxon signed-rank test and the McNemar tests. Conditional logistic regression, which takes into account the matched nature of the data, ${ }^{17}$ was used to identify predictors of early mortality and to study the impact of the type of surgery on 30-day survival. Survival was determined by Kaplan-Meier methodology, and curves were compared using the test described by Klein and Moeschberger. ${ }^{17}$ A Cox regression model with robust standard errors that 
TABLE 1. Preoperative demographic, clinical, and echocardiographic data

\begin{tabular}{|c|c|c|c|}
\hline Variable & Repair $(n=244)$ & Replacement $(n=244)$ & Standardized difference \\
\hline Age, $y ;$ mean \pm SD & $66.0 \pm 7.1$ & $66.1 \pm 8.0$ & 0.036 \\
\hline Sex, male/female; n (\%) & $178 / 66(72.9 / 27.1)$ & $169 / 75(69.2 / 30.8)$ & 0.081 \\
\hline $\mathrm{BSA}, \mathrm{kg} / \mathrm{m}^{2} ;$ mean $\pm \mathrm{SD}$ & $1.79 \pm 1.2$ & $1.78 \pm 1.2$ & 0.022 \\
\hline NYHA functional class, mean \pm SD & $2.8 \pm 1.2$ & $2.8 \pm 1.3$ & 0.000 \\
\hline EuroSCORE, mean $\pm \mathrm{SD}$ & $12.9 \pm 3.0$ & $13.0 \pm 3.0$ & 0.057 \\
\hline Family history, n (\%) & $131(53.6)$ & $137(56.1)$ & 0.050 \\
\hline Hypertension, $\mathrm{n}(\%)$ & $101(41.3)$ & $99(40.5)$ & 0.016 \\
\hline Diabetes mellitus, n (\%) & $89(36.4)$ & $86(35.2)$ & 0.025 \\
\hline COPD, n $(\%)$ & $48(19.6)$ & $51(20.9)$ & 0.032 \\
\hline CRD, n $(\%)$ & $68(27.8)$ & $72(29.5)$ & 0.037 \\
\hline CVD, n $(\%)$ & $19(7.7)$ & $22(9.0)$ & 0.046 \\
\hline PVD, n (\%) & $12(4.9)$ & $13(5.3)$ & 0.018 \\
\hline $\mathrm{AF}, \mathrm{n}(\%)$ & $30(12.2)$ & $32(13.1)$ & 0.027 \\
\hline Pulmonary hypertension, n (\%) & $21(8.6)$ & $23(9.4)$ & 0.028 \\
\hline History of CHF, n (\%) & $123(50.4)$ & $127(52.0)$ & 0.032 \\
\hline IABP, n (\%) & $78(31.9)$ & $75(30.7)$ & 0.025 \\
\hline \multicolumn{4}{|l|}{ MI localization, n (\%) } \\
\hline Anterior & $62(25.5)$ & $64(26.2)$ & 0.015 \\
\hline Lateral & $60(24.5)$ & $61(25.0)$ & 0.011 \\
\hline Inferoposterior & $122(50.0)$ & $119(48.8)$ & 0.024 \\
\hline Left main CAD & $56(22.9)$ & $56(21.9)$ & 0.000 \\
\hline \multicolumn{4}{|l|}{ Echocardiographic data } \\
\hline $\mathrm{LVEF}, \%$; mean $\pm \mathrm{SD}$ & $35.0 \pm 3.2$ & $34.9 \pm 2.9$ & 0.057 \\
\hline $\mathrm{EDD}, \mathrm{mm} ;$ mean $\pm \mathrm{SD}$ & $55.0 \pm 7.2$ & $55.2 \pm 6.9$ & 1.075 \\
\hline $\mathrm{ESD}, \mathrm{mm} ;$ mean $\pm \mathrm{SD}$ & $42.0 \pm 7.0$ & $42.2 \pm 7.3$ & 0.074 \\
\hline $\mathrm{EDV}, \mathrm{mL} ;$ mean $\pm \mathrm{SD}$ & $173 \pm 25.3$ & $173 \pm 27.2$ & 0.000 \\
\hline $\mathrm{ESV}, \mathrm{mL} ;$ mean $\pm \mathrm{SD}$ & $108 \pm 16.6$ & $108 \pm 18.7$ & 0.000 \\
\hline $\mathrm{MR}$, grade; mean $\pm \mathrm{SD}$ & $2.8 \pm 0.5$ & $2.8 \pm 0.5$ & 0.000 \\
\hline
\end{tabular}

$S D$, Standard deviation; $B S A$, body surface area; $N Y H A$, New York Heart Association; $C O P D$, chronic obstructive pulmonary disease; $C R D$, chronic renal disease; $C V D$, cerebral vascular disease; $P V D$, peripheral vascular disease; $A F$, atrial fibrillation; $C H F$, congestive heart failure; $I A B P$, intra-aortic balloon pump; $M I$, myocardial infarction; $C A D$, coronary artery disease; $L V E F$, left ventricular ejection fraction; $E D D$, end diastolic diameter; $E S D$, end systolic diameter; $E D V$, end diastolic volume; $E S V$, end systolic volume; $M R$, mitral regurgitation.

accounted for the clustering of matched pairs was used to identify predictors of late death and to estimate the association of the type of surgery with late mortality. ${ }^{17,18}$

Competing risk analysis was used to avoid overestimation of the incidence of valve-related death, cardiac-related death, and valve-related complications. First, a competing risk analysis with death as a competing event was performed to assess the cumulative incidence curves of these nonfatal events. ${ }^{13}$ The curves were also compared between the subgroups of patients. Then, a multivariable competing risk analysis was performed to identify the independent risk factors for valve-related reoperation. We carried out the competing risk regression model on the matched data, including the treatment group indicator and all the covariates (the variables put into the PS).

The influence of attempted valve repair, converted to replacement in the same operation, was assessed in 2 ways. First, among propensity-matched pairs, the variable attempted repair (crossover from repair to replacement during the same operative session) was added to the multivariable models used to compare valve repair versus replacement. Second, matched patients were compared strictly as intent-to-treat. Furthermore, to take into account the volume of the referring centers, we also add a volume categoric variable into the model $(400 \leq 600$ operations/year, $600-1000$ operations/year, $>1000$ operations/year).

Analyses were performed using SAS, release 9.2 (SAS Institute, Cary, NC), SPSS 12.0 (SPSS, Chicago, Ill), and Graph Pad Prism release 5 (Graph Pad Software Inc, La Jolla, Calif) statistical packages.

\section{RESULTS}

\section{Overall Survival and Adverse Events}

Thirty-seven patients (3.7\%) died within 30 days and 137 patients $(6.8 \%)$ died during the follow-up. Five- and 8-year freedom from death were $75.5 \% \pm 3.5 \%$ and $72.0 \% \pm$ $3.0 \%$, respectively. Cumulative incidences of valverelated death was $2.0 \%$ (95\% confidence interval [CI], 1.6-2.7) whereas cumulative incidences of cardiac-related death was $33.5 \%$ (95\% CI, 27.4-41.3).

There were 148 valve-related reoperations $(14.7 \%)$. Causes of reoperation were endocarditis in 24 patients, repair failure in 106 patients, structural valve degeneration (SVD) in 14 patients, and paravalvular leak in 4 patients. Cumulative incidences of valve-related reoperation was $43.7 \%(95 \% \mathrm{CI}$, 30.1-50.0). Last, cumulative incidence of all valve-related complications was $27.2 \%$ (95\% CI, 21.9-34.7).

\section{Balance Diagnostics}

Prematching baseline and operative data are shown in Appendix 1 and Appendix 2, respectively. Prematching 
TABLE 2. Operative data

\begin{tabular}{|c|c|c|c|}
\hline Variable & $\begin{array}{c}\text { Repair } \\
(\mathrm{n}=\mathbf{2 4 4})\end{array}$ & $\begin{array}{c}\text { Replacement } \\
(\mathrm{n}=\mathbf{2 4 4})\end{array}$ & $\begin{array}{c}\text { Standardized } \\
\text { difference }\end{array}$ \\
\hline $\mathrm{CPB}$ time, min; mean $\pm \mathrm{SD}$ & $145 \pm 33$ & $145 \pm 30$ & 0.000 \\
\hline ACC time, min; mean \pm SD & $94 \pm 34$ & $94 \pm 28$ & 0.000 \\
\hline \multicolumn{4}{|l|}{ Distal anastomoses, n (\%) } \\
\hline 1 & $95(38.9)$ & $100(40.9)$ & \\
\hline $2-4$ & $144(59.0)$ & $137(56.2)$ & \\
\hline$>4$ & $5(2.1)$ & 7 (2.9) & \\
\hline $\begin{array}{l}\text { Anastomoses/patient, } \\
\text { mean } \pm \mathrm{SD}\end{array}$ & $2.2 \pm 0.2$ & $2.2 \pm 0.2$ & 0.000 \\
\hline $\begin{array}{l}\text { Failed mitral valve repair, } \\
\qquad \mathrm{n}(\%)\end{array}$ & - & $3(1.2)$ & - \\
\hline $\begin{array}{l}\text { Arterial graft/patient, } \\
\text { mean } \pm \mathrm{SD}\end{array}$ & $1.4 \pm 0.2$ & $1.4 \pm 0.4$ & 0.000 \\
\hline \multicolumn{4}{|l|}{ Ring size, n (\%) } \\
\hline $26 \mathrm{~mm}$ & $66(27.1)$ & - & - \\
\hline $28 \mathrm{~mm}$ & $128(52.5)$ & - & - \\
\hline $30 \mathrm{~mm}$ & $31(12.7)$ & - & - \\
\hline $32 \mathrm{~mm}$ & $14(5.7)$ & - & - \\
\hline $34 \mathrm{~mm}$ & $3(1.2)$ & - & - \\
\hline $36 \mathrm{~mm}$ & $2(0.8)$ & - & - \\
\hline Mean \pm SD & $28.0 \pm 3.4$ & - & - \\
\hline Median (IQR) & $28(26-28)$ & - & - \\
\hline Ring type, n (\%) & & - & - \\
\hline $\begin{array}{l}\text { Carpentier Edwards } \\
\text { Classic }\end{array}$ & $36(14.7)$ & - & - \\
\hline $\begin{array}{l}\text { Carpentier Edwards } \\
\text { Physio }\end{array}$ & $89(36.5)$ & - & - \\
\hline $\begin{array}{l}\text { Carpentier Edwards } \\
\text { Physio II }\end{array}$ & $74(30.3)$ & - & - \\
\hline $\begin{array}{l}\text { Carpentier } \\
\text { McCarthyETlogix }\end{array}$ & $8(3.3)$ & - & - \\
\hline Geoform & - & - & - \\
\hline St Jude Medical Seguin & $4(1.6)$ & - & - \\
\hline $\begin{array}{l}\text { St Jude Medical Rigid } \\
\text { Saddle }\end{array}$ & - & - & - \\
\hline Sorin Memo 3D & $33(13.6)$ & - & - \\
\hline \multicolumn{4}{|l|}{ Prosthesis size, n (\%) } \\
\hline $25 \mathrm{~mm}$ & - & $46(18.8)$ & - \\
\hline $27 \mathrm{~mm}$ & - & 87 (35.7) & - \\
\hline $29 \mathrm{~mm}$ & - & 95 (38.9) & - \\
\hline $31 \mathrm{~mm}$ & - & $11(4.6)$ & - \\
\hline $33 \mathrm{~mm}$ & - & $5(2.0)$ & - \\
\hline Mean \pm SD & - & $27.7 \pm 1.8$ & - \\
\hline Median (IQR) & - & $27(27-29)$ & - \\
\hline \multicolumn{4}{|l|}{ Prosthesis type, n (\%) } \\
\hline \multicolumn{4}{|l|}{ Biologic } \\
\hline Carpentier Edwards & - & $74(57.3)$ & - \\
\hline $\begin{array}{l}\text { Carpentier Edwards } \\
\text { MAGNA }\end{array}$ & - & $4(3.1)$ & - \\
\hline Sorin Mitroflow & - & $16(12.5)$ & - \\
\hline Medtronic Hancock II & - & $5(3.9)$ & - \\
\hline Medtronic Mosaic & - & $25(19.4)$ & - \\
\hline St Jude Medical Epic & - & $5(3.8)$ & - \\
\hline Labcor & - & - & - \\
\hline Moore & - & - & - \\
\hline
\end{tabular}

TABLE 2. Continued

\begin{tabular}{lccc}
\hline \multicolumn{1}{c}{ Variable } & $\begin{array}{c}\text { Repair } \\
(\mathbf{n}=\mathbf{2 4 4})\end{array}$ & $\begin{array}{c}\text { Replacement } \\
(\mathbf{n}=\mathbf{2 4 4})\end{array}$ & $\begin{array}{c}\text { Standardized } \\
\text { difference }\end{array}$ \\
\hline Mechanical & & & \\
$\quad$ St Jude Medical & - & $12(10.4)$ & - \\
$\quad$ Sorin Bicarbon & - & $9(7.8)$ & - \\
Carbomedics & - & $40(34.9)$ & - \\
ATS & - & $1(0.8)$ & - \\
On-X & - & $53(46.1)$ & - \\
Mitral leaflets preservation, & & & \\
$\quad$ n (\%) & - & $43(37.4)$ & - \\
$\quad$ None & - & $24(20.9)$ & - \\
Posterior & - & $48(41.7)$ & - \\
$\quad$ Both & & & \\
\hline$C P B$, Cardiopulmonary bypass; $S D$, standard deviation; $A C C$, aortic crossclamp; \\
$I Q R$, interquartile range.
\end{tabular}

standardized differences exceeded 0.1 for 24 of the 31 covariates $(75.8 \%)$. Median prematching standardized difference was 0.170 (IQR, 0.105-0.369). The resultant matched sample consisted of 244 matched pairs. Tables 1 and 2 show postmatching baseline and operative data. The postmatching median standardized difference was 0.024 (IQR, 0-0.037), and in none of the covariates did it exceed 0.1 (Figure 1).

\section{Propensity-Adjusted Early and Long-Term Survival}

The early (30-day) mortalities were $3.3 \%(\mathrm{n}=8)$ for MVP and 5.3\% $(\mathrm{n}=13)$ for MVR $(P=.32)$. Multivariable analysis revealed that independent predictors of operative mortality were age, EuroSCORE $\geq 12$, cardiopulmonary bypass time, and aortic crossclamping time (Table 3), whereas MVP provided no significant benefit over MVR.

During follow-up, 36 patients (14.7\%) undergoing repair and 41 patients $(16.8 \%)$ in the replacement group died $(P=.51 ; 1.8$ patient/year for MVP and 1.5 patient/year for MVR) Survival (Figure 2, $A$ ) for the MVP population was $85.3 \% \pm 2.6 \%$ at 5 years and $81.6 \% \pm 2.8 \%$ at 8 years. Survival for the MVR population was $86.1 \% \pm$ $2.5 \%$ at 5 years and $79.6 \% \pm 4.8 \%$ at 8 years $(P=.42)$. Five- and 8-year survival for patients with LVEF $>30 \%$ (Figure $2, B$ ) was $82.2 \% \pm 2.6 \%$ and $78.5 \% \pm 3 \%$ in MVP and MVR $(P=.78)$, respectively, and $62.1 \% \pm$ $3.8 \%(P<.001$ vs LVEF $>30 \%)$ and $60.1 \% \pm 3.0 \%$ $(P<.001$ vs LVEF $>30 \%)$ in patients with LVEF $\leq 30 \%$ $(P=.82)$, respectively. In the MVR group, 8-year survival was not significantly different between biologic and mechanical prostheses $(81.4 \% \pm 2.7 \%$ vs $77.8 \% \pm 2.9 \%$; $P=.45)$.

Cumulative incidences of valve-related death (Figure 3, $A$ ) were $1.3 \%(95 \% \mathrm{CI}, 0.9-1.8)$ in MVP and $2.2 \%(95 \%$ CI, 1.7-2.8) in MVR $(P=.1)$, whereas cumulative incidences of cardiac-related death (Figure $3, B$ ) were $22.1 \%$ (95\% CI, 18.3-27.1) and 20.2\% (95\% CI, 15.4-25.3) in 


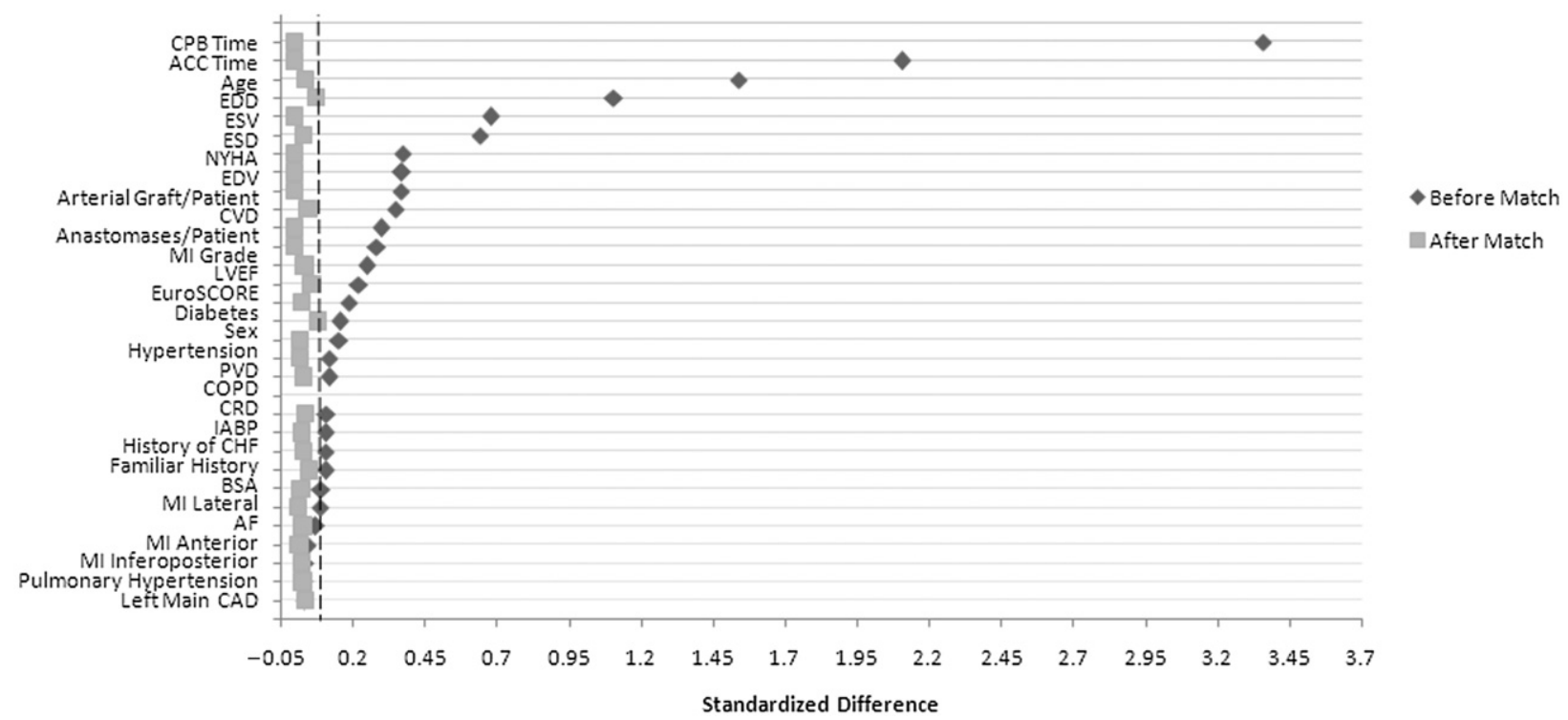

FIGURE 1. Absolute standardized differences before and after propensity score matching comparing covariates values for patients undergoing mitral valve repair or replacement (see text). $C P B$, Cardiopulmonary bypass; $A C C$, aortic crossclamp; $E D D$, end diastolic diameter; $E S V$, end systolic volume; $E S D$, end systolic diameter; $N Y H A$, New York Heart Association; $E D V$, end diastolic volume; $C V D$, cerebral vascular disease; $M I$, myocardial infarction; $L V E F$, left ventricular ejection fraction; $P V D$, peripheral vascular disease; $C O P D$, chronic obstructive pulmonary disease; $C R D$, chronic renal disease; $I A B P$, intraaortic balloon pump; $C H F$, congestive heart failure; $B S A$, body surface area; $A F$, atrial fibrillation; $C A D$, coronary artery disease.

MVP and MVR, respectively $(P=.55)$. Multivariate predictors of late mortality were age (hazard ratio [HR], 1.4; $P<.001)$, chronic renal failure $(\mathrm{HR}, 2 ; P<.001)$, and LVEF (HR, $1.3 ; P=.02$ ). The type of mitral procedure was not a significant predictor of late death (Table 3; HR, $1.0 ; P=.5)$.

\section{Propensity-Adjusted Long-Term Adverse Events and Clinical Status}

At follow-up, recurrence of mitral valve regurgitation in MVP was $25 \%$ (61 patients, 4 with endocarditis). In MVR, there were 4 patients with MR $\geq 2+$ because of a paravalvular leak $(1.6 \%)$ and 11 because of bacterial endocarditis (4.5\%). In patients with MVR using tissue valves, 11 patients $(6.4 \%)$ showed significant steno/insufficiency-type structural valve degeneration (SVD).

Among propensity-matched patients, there were $65 \mathrm{mi}-$ tral valve reoperations, 39 in the MVP group (endocarditis, $\mathrm{n}=4$; repair failure, $\mathrm{n}=35$ ) and 26 in the MVR group (19/ 129 who received a bioprosthetic [SVD, $\mathrm{n}=11$; endocarditis, $n=6$; paravalvular leaks, $n=2]$ and $7 / 115$ who received a mechanical prosthesis [endocarditis, $\mathrm{n}=5$; paravalvular leaks, $\mathrm{n}=2]$ ).

Cumulative incidences of valve-related reoperations (Figure 3, C) were 46.2\% (95\% CI, 31.8-51.4) in MVP and $31.3 \%(95 \% \mathrm{CI}, 26.6-37.8)$ in $\operatorname{MVR}(P=.01)$, whereas the cumulative incidences of valve-related reoperations in biologic and mechanical prostheses (Figure 3, D) were $21.3 \%(95 \% \mathrm{CI}, 16.8-26.6, P=.007$ vs $\mathrm{MVP})$ and $10.4 \%(95 \% \mathrm{CI}, 6.5-15.1, P<.001$ vs $\mathrm{MVP})$, respectively.

The cumulative incidence of SVD in patients $<70$ years receiving a bioprosthetic valve (Figure $3, E$ ) was $18.3 \%$ (95\% CI, 13.7-23.9), whereas in patients $\geq 70$ years, it was $9.2 \%(95 \% \mathrm{CI}, 5.7-13.4, P<.001)$.

Last, cumulative incidences of all valve-related complications (Figure 3, $F$ ) were 23.3\% (95\% CI, 17.8-29.0) in MVP and $18.4 \%(95 \% \mathrm{CI}, 13.6-23.7)$ in MVR $(P=.38)$.

Multivariable competing risk regression (Table 3) identified age (HR, 2.4; $P=.03$ ) and type of procedure (HR, 2.9; $P<.001)$ as multivariate predictors of valve-related reoperation.

At follow-up, median NYHA functional class was 1.6 (IQR, 1.2-2.0) in MVP and 1.6 (IQR, 1.3-2.0) in MVR $(P>9)$, respectively. Left ventricular ejection fraction did not improve significantly from baseline in both groups (MVP, $36.9 \pm 3.5$ vs MVR, $38.5 \pm 3.3 ; P=.66$ ). Last, in MVR patients, LVEF was higher in patients with total mitral apparatus preservation $(41.2 \pm 2.9)$ and isolated posterior leaflet preservation $(39.1 \pm 2.8)$ than in patients with no leaflet preservation $(36.3 \pm 2.6)$, although the difference did not reach statistical significance $(P=.07)$.

\section{DISCUSSION \\ Key Findings}

Our study shows that, in patients affected by CIMR and LV dysfunction, MVP and MVR have similar results in 
TABLE 3. Univariable and multivariable analyses

\begin{tabular}{|c|c|c|c|c|}
\hline \multirow[b]{2}{*}{ Predictors } & \multicolumn{2}{|c|}{ Univariable } & \multicolumn{2}{|c|}{ Multivariable } \\
\hline & $\begin{array}{c}P \\
\text { value } \\
\end{array}$ & $\begin{array}{c}\text { OR } \\
(95 \% \text { CI }) \\
\end{array}$ & $\begin{array}{c}P \\
\text { value } \\
\end{array}$ & $\begin{array}{c}\text { OR } \\
(95 \% \text { CI }) \\
\end{array}$ \\
\hline \multicolumn{5}{|l|}{ Predictors of early mortality } \\
\hline Age & $<.001$ & $2.3(1.7-2.9)$ & $<.001$ & $2.1(1.6-2.7)$ \\
\hline Male sex & .07 & $1.2(0.8-1.9)$ & .1 & $1.1(0.7-1.9)$ \\
\hline NYHA functional class & .03 & $1.4(0.8-2.1)$ & .07 & $1.2(0.8-1.8)$ \\
\hline EuroSCORE $\geq 12$ & .01 & $1.8(1.3-2.5)$ & .009 & $2.0(1.5-2.6)$ \\
\hline Pulmonary hypertension & .01 & $2.1(1.8-2.7)$ & .05 & $1.9(1.3-2.5)$ \\
\hline CRD & .04 & $1.3(0.9-1.7)$ & .07 & $1.2(0.8-1.7)$ \\
\hline LVEF & .07 & $1.1(0.8-1.7)$ & .09 & $1.1(0.6-1.6)$ \\
\hline MR & .05 & $1.4(0.9-1.8)$ & .1 & $1.2(0.7-1.7)$ \\
\hline $\mathrm{CPB}$ time, $\min$ & $<.001$ & $2.3(1.9-2.9)$ & $<.001$ & $2.3(2.0-3.0)$ \\
\hline ACC time, $\min$ & $<.001$ & $2.0(1.6-2.7)$ & $<.001$ & $2.2(1.9-2.8)$ \\
\hline MVP vs MVR & .08 & $1.1(0.8-1.8)$ & .1 & $1.1(0.8-1.7)$ \\
\hline Propensity score & .03 & $1.3(0.8-1.8)$ & .1 & $1.1(0.9-1.6)$ \\
\hline \multicolumn{5}{|l|}{ Predictors of late mortality* } \\
\hline Age & $<.001$ & $1.4(1.3-2.2)$ & $<.001$ & $1.4(1.3-2.2)$ \\
\hline COPD & .06 & $1.2(0.9-1.8)$ & .2 & $1.1(0.6-1.7)$ \\
\hline CRD & $<.001$ & $2.2(1.9-2.7)$ & $<.001$ & $2.0(1.7-2.5)$ \\
\hline LVEF & .02 & $1.4(1.0-1.9)$ & .02 & $1.3(1.0-1.8)$ \\
\hline MVP vs MVR & .08 & $1.1(0.7-1.4)$ & .2 & $1.1(0.5-1.3)$ \\
\hline Propensity score & .006 & $1.4(1.1-2.0)$ & .5 & $1.05(0.5-1.4)$ \\
\hline \multicolumn{5}{|c|}{ Predictors of valve-related reoperation $\dagger$} \\
\hline Age & .005 & $2.4(2.2-3.1)$ & .03 & $2.4(2.0-3.0)$ \\
\hline MVP vs MVR & $<.001$ & $2.9(2.7-3.1)$ & $<.001$ & $2.9(2.5-3.2)$ \\
\hline Propensity score & .07 & $2.3(1.9-2.6)$ & .12 & $1.1(0.8-1.5)$ \\
\hline $\begin{array}{l}O R \text {, Odds ratio; } C I \text {, confidence ir } \\
\text { chronic renal disease, } L V E F \text {, left } \\
\text { tion; } C P B \text {, cardiopulmonary by } \\
\text { plasty; } M V R \text {, mitral valve replac }\end{array}$ & $\begin{array}{l}\text { interval; } N \\
\text { ft ventricu }\end{array}$ & $\begin{array}{l}\text { NYHA, New Yor } \\
\text { lar ejection frac }\end{array}$ & Heart & $\begin{array}{l}\text { sociation; } C R D, \\
\text { nitral regurgita- } \\
P, \text { mitral valve } \\
\text { pulmonary dis- } \\
\text { unts for cluster- }\end{array}$ \\
\hline
\end{tabular}

terms of short- and long-term survival. Furthermore, no difference was found between groups with regard to late LV function, cardiac- and valve-related death, and patient functional capacity. In contrast, patients who underwent MVP exhibited a higher incidence of MR recurrence compared with patients who underwent valve replacement. Last, MVP resulted in being a strong predictor of valve-related reoperation.

\section{Early and Late Survival}

Hospital or 30-day mortality of patients with heterogeneous CIMR has been shown to be as low as $4 \%$ to $5 \%$ in recent series. ${ }^{8,9}$ Our findings, although derived from surgery carried out in selected and elective surgical candidates, are in the same range, confirming that patient with CIMR, even with LV impairment, may indeed undergo MR correction and associated $\mathrm{CABG}$ with favorable early outcome. In previous series, better early survival in low-risk MVP patients compared with similar MVR patients has been reported, whereas equal or even better results with MVR have been documented in high-risk
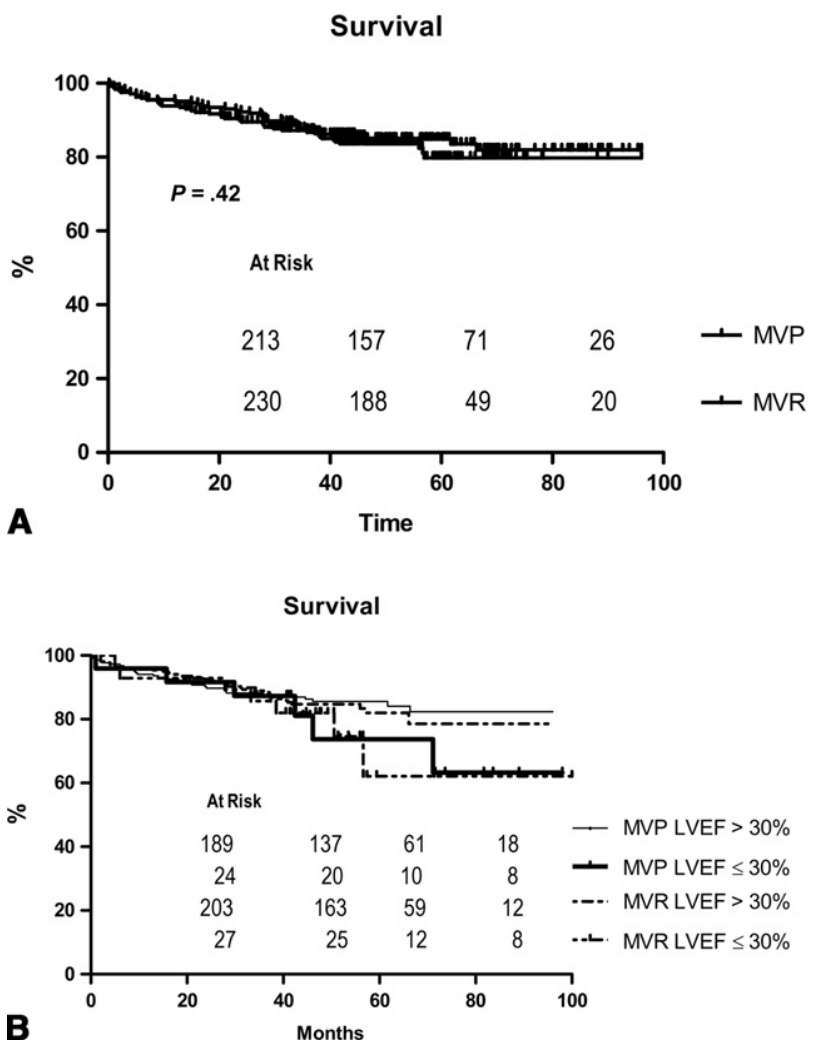

FIGURE 2. A, Actuarial survival in mitral valve repair $(M V P)$ and mitral valve replacement $(M V R)$. B, Actuarial survival in MVP and MVR by left ventricular ejection fraction $(L V E F)$.

cases. ${ }^{11,12}$ More recent experiences have failed to detect any substantial difference between the 2 surgical options in terms of in-hospital or 30-day mortality, and are in accordance with our observations. ${ }^{8-10}$ Furthermore, the exclusion of emergency patients, reoperations, and complex cases (mitral valve surgery $+\mathrm{CABG}+$ other associated procedures) in our data analysis allowed us to focus on the true impact of mitral surgery type and myocardial revascularization on perioperative mortality in patients with CIMR, confirming that only age, EuroSCORErelated preoperative risk factors, and operative times act as negative predictors for short-term prognosis, whereas the application of MVP or MVR does not apparently exert any inference.

In relation to late outcome, published series have provided a wide range of results. In 1995, Cohn and associates ${ }^{19}$ reported a 5 -year survival of $56 \%$ and $91.5 \%$ in MVP and MVR, respectively. More recent series have shown a 5-year life expectancy that varies from $44 \%$ to $79.3 \%$ in MVP patients, and from $47 \%$ to $73.4 \%$ in MVR subjects. ${ }^{6-9}$ This ample range may be explained by the heterogeneity of patient cohorts that variably included patients operated for acute MR, patients in cardiogenic shock, patients with incomplete or without CABG surgery, or patients with other associated cardiac 

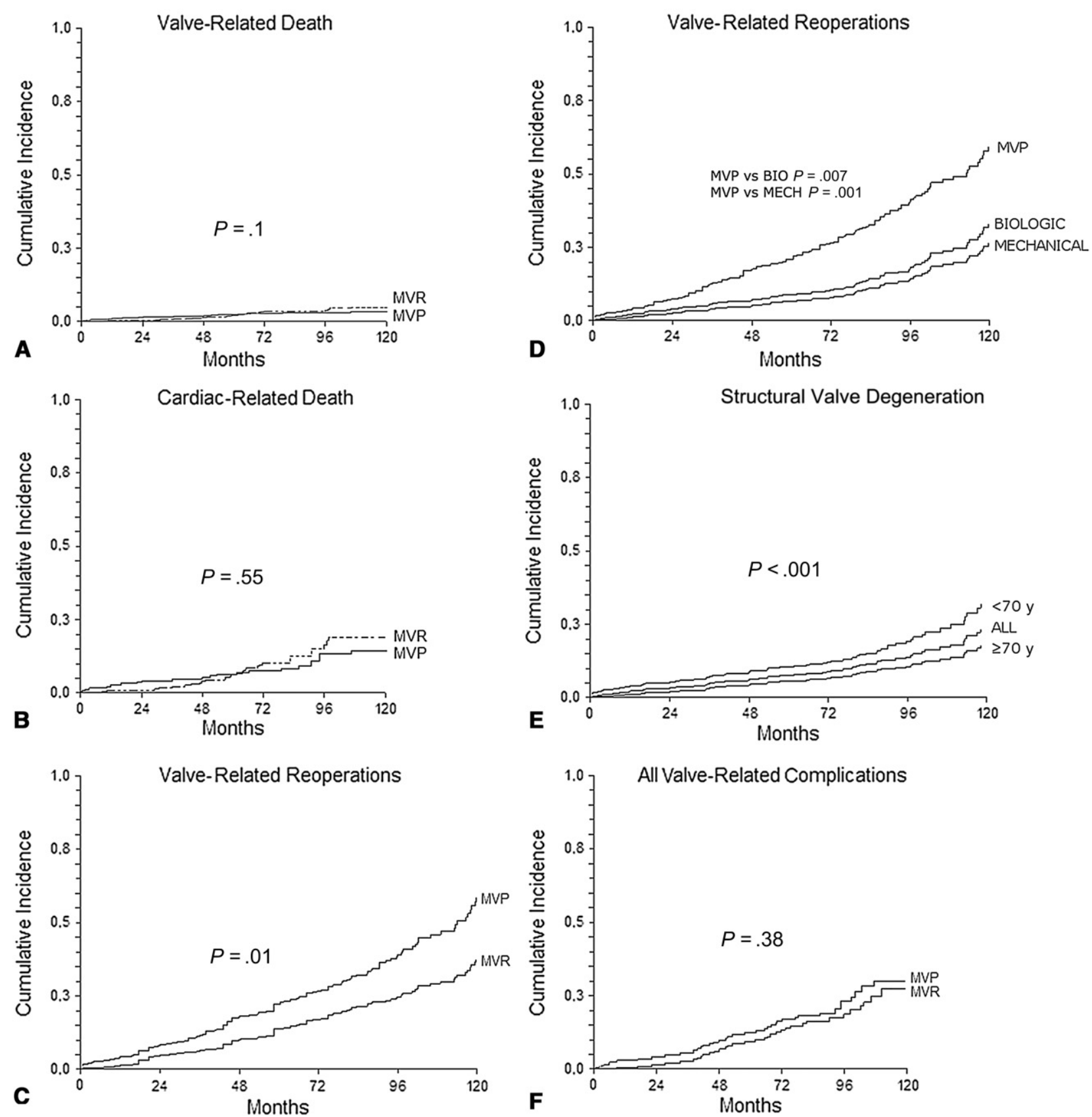

FIGURE 3. A, Cumulative incidence plots depicting valve-related death. B, Cumulative incidence plots depicting cardiac-related death. C, Cumulative incidence plots depicting valve-related reoperations. D, Cumulative incidence plots depicting valve-related reoperations in biological vs mechanical prostheses. E, Cumulative incidence plots depicting structural valve deteriorations. F, Cumulative incidence plots depicting all valve-related complications. $M V R$, Mitral valve replacement; $M V P$, mitral valve plasty; $B I O$, biologic; $M E C H$, mechanical.

procedures. ${ }^{6}$ In our CIMR series, which included only patients undergoing MVP or MVR electively with complete myocardial revascularization, 8-year survival showed favorable results regardless the type of mitral valve surgery and despite the presence of moderate impairment of LV function. Our survival figures resembled the recent series of Magne and colleagues, ${ }^{10}$ who reported an 8-year survival in propensity score-matched cohorts of $65 \%$ in
MVP patients versus $68 \%$ in MVR cases. In contrast, Maltais and coworkers ${ }^{8}$ have reported overall survival of $55 \%$ and $24 \%$ at 5 and 10 years, respectively, in patients with CIMR with ischemic cardiomyopathy (LVEF $<45 \%$ ). Such a discrepancy with our data may be explained, again, by the exclusion from our data analysis of reoperations, emergency cases, and complex operations, which accounted for $19 \%, 3.4 \%, 15 \%$, 
respectively, and by the lower preoperative LVEF in the study of the Mayo Clinic. ${ }^{8}$

In our experience, cardiac- and valve-related mortality were also similar between groups, and type of intervention was not a significant predictor of late death.

\section{Recurrence of Mitral Regurgitation and Need of Reoperation}

Concern has been raised about a high incidence of persistent or recurrent MR following restrictive annuloplasty in patients with CIMR. Postoperative recurrence rate of moderate/severe MR has been shown to be as much as $33 \%$ of the patients at 6 months, or more than $70 \%$ at 5 years. ${ }^{20,21}$ In our study, MR occurred in $25 \%$ of MVP patients in the long term, and repair was related directly to higher likelihood of reoperation. Although predictors of reappearance or deterioration of MR have been related to preoperative features of mitral valve anatomic features or to LV geometry and dimensions, ${ }^{14,22,23}$ suggesting which patients might be considered MVP responders in CIMR, it seems unquestionable that, also in the presence of intraoperative successful MVP, recurrence of MR still represents a disappointing and not unusual complication in patients with CIMR submitted to mitral valve annuloplasty.

Replacing the mitral valve, however, does not confer, as expected, long-lasting freedom from valve-related dysfunction and reoperation. With regard to the use of MVR in CIMR, current opinion apparently favors the use of tissue valves for the ease of preserving the mitral leaflets and avoidance of postoperative anticoagulationrelated adverse events. ${ }^{3-5}$ Our findings, however, indicate that, based on the rather favorable mid- and long-term prognoses of these patients, bioprosthetic degeneration might represent another potential shortcoming or complication to be confronted during the postoperative lifetime of patient with CIMR who undergo MVR, although, apparently, with a reduced rate compared with recurrent MR in MVP patients.

Acute endocarditis was responsible for recurrent MR in $1.6 \%$ of MVP patients and in $4.5 \%$ of MVR subjects. This aspect has been rarely addressed or reported in previous studies, although Grossi and associates ${ }^{12}$ showed a 3\% rate of acute valvular infection in patients who underwent MVR, and Chan and colleagues ${ }^{9}$ found a $1.5 \%$ incidence in their MVP patients. Further analysis is warranted to confirm the actual incidence of such an adverse event in patients with CIMR.

\section{Impact of Surgery on Left Ventricular Function}

A small improvement in LV function following MVP or MVR and CABG for ischemic MR has been reported by Calafiore and associates. ${ }^{22}$ In a recent study, no change in postoperative $\mathrm{LV}$ function was observed in $18 \%$ of patients operated either with MVP or MVR, deteriorated LV contractility was shown in $20 \%$ of MVP patients versus $16 \%$ of MVR patients, and improved LV performance accounted for less than one-third of patients in both surgical cohorts, respectively. ${ }^{9}$ De Bonis and collaborators ${ }^{23}$ showed that LV functional improvement could be achieved only in $50 \%$ of patients operated with successful MVP for ischemic or dilated cardiomyopathy, and such a positive contractile change was associated with LV reverse remodeling. Noteworthy, in contrast to a variable effect as far as LV performance or LV dimension is concerned, functional capacity or quality of life appear to be improved substantially after surgery in the long term in the majority of patients with CIMR patients. ${ }^{4,22,23}$ Lack of improvement or deterioration of LV contractile performance may have several explanations, but surgery performed beyond the point of no return of LV remodeling, further evolution of coronary artery disease, and persistence or recurrence of MR may all play a critical role. ${ }^{2,4}$

It is generally agreed that preserving the mitralventricular continuity during MVR has a beneficial effects in terms of early and long-term outcome. ${ }^{24}$ There is still no definite evidence, however, about the superiority of bileaflet sparing versus isolated posterior leaflet preservation alone. ${ }^{4,24}$ In our experience, albeit limited by the inherent bias of the study, a trend toward a beneficial effect of chordal sparing MVR (62.6\% of our patients) versus severance of the annular ventricular continuity was shown, with a greater, although not significant, benefit regarding LV function when both MV leaflets were maintained. Further studies are unquestionably warranted to elucidate conclusively these peculiar aspects of MVR.

\section{Limitations}

This study has the well-known and relevant shortcomings of a retrospective, multicenter, PS analysis. In addition, other limitations must be pointed out. First, when performing a propensity-matched analysis, there is always a risk of losing an important subgroup of patients that were not matched. In this study, selection bias is introduced at the time of decision to perform surgery because the decision to perform MVR may be related to the complexity of the patient and the experience of the surgeon. Therefore, matched repair patients might represent a sicker group of patients, which in turn may potentially indicates that MVP is not as good for a specific high-risk group of patients. Appropriate and consistent patient matching, however, was achieved effectively in a robust patient population. Furthermore, the common heterogeneity of other similar published studies was carefully addressed by strict patient selection criteria.

Second, this study is heterogeneous (several centers and 15 years' inclusion time) and this takes into account when examining our findings because the approach to functional mitral valve insufficiency has changed during the past 15 
years. Third, there was a large variability in follow-up time. Indeed after 15 years there might be more MR recurrence and reoperation for valve degeneration compared with a shorter follow-up. Fourth, there is no information about tricuspid valve function, which may have been very important in the setting of ventricular dilation. Fifth, we failed to provide information on the excluded MVP patients with more than $2+$ MR at discharge, which could have been of interest and value for future interpretation.

Sixth, preoperative information about the exact mechanisms and characteristics of preoperative MR and the postrepair mitral valve features (coaptation height and coaptation depth, for instance) were not available in all patients, making comparative investigations among pre-, intra-, and postoperative mitral valve performance unfeasible. For this reason, the objectives of this study were, exclusively, early and late outcomes, and not determination of favorable or negative predictors in relation to mitral valve-related preoperative variables.

The patient population included subjects with coronary artery disease, CIMR, and LV dysfunction. Information about detection of myocardial viability was not available in all patients, thereby impeding any further analysis in this respect regarding the presence or absence of revascularized viable myocardium on postoperative $\mathrm{LV}$ function. It is likely, however, that these patients exhibited favorable conditions for perioperative management and expected benefit from myocardial revascularization.

In terms of surgical procedure, preservation of mitral subvalvular apparatus was carried out in only $66 \%$ of patients, and was applied variably according to surgeons' preference and indications. Furthermore, no detailed information was available regarding mechanisms of recurrent MR at follow up.

Last, postoperative data regarding LV diameters and volumes related to the type of procedure and/or other factors (leaflet preservation in MVR) were not included in this study and will be object of a companion analysis.

\section{CONCLUSIONS}

Our retrospective, multicenter, PS-based study indicates that MVP apparently did not confer any substantial benefit compared with MVR in terms of early- and long-term survival, valve-related complication rates, and effects on $\mathrm{LV}$ performance. In contrast, it exposes operated patients to higher recurrence of MR and to higher reoperation rate. Therefore, MVR appears to be a valuable surgical option for patients with CIMR and LV dysfunction undergoing mitral valve surgery and CABG. Nonetheless, SVD should be taken into consideration when tissue valves are implanted, based on a favorable postoperative life expectancy. An ongoing, randomized trial in patients with CIMR is paramount for providing conclusive insight into the appropriate management of such an increasing patient population. ${ }^{25}$
We gratefully acknowledge Mrs Judith Wilson for the English revision of this article. Our heartfelt thanks to Prof Eugene Blackstone for his suggestions about competing risk regression.

\section{References}

1. Grigioni F, Enriquez-Sarano M, Zehr KJ, Bailey KR, Tajik AJ. Ischemic mitral regurgitation: long-term outcome and prognostic implications with quantitative Doppler assessment. Circulation. 2001;103:1759-64.

2. Pierard LA, Carabello BA. Ischaemic mitral regurgitation: pathophysiology, outcomes and the conundrum of treatment. Eur Heart J. 2010;31:2996-3005.

3. LaPar DJ, Kron IL. Should all ischemic mitral regurgitation be repaired? When should we replace? Curr Opin Cardiol. 2011;26:113-7.

4. Bouma W, van der Horst ICC, Wijdh-den Hamer IJ, Erasmus ME, Zijlstra F, Mariani MA, et al. Chronic ischemic-based mitral regurgitation: current treatment results and new mechanism-based surgical approaches. Eur J Cardiothorac Surg. 2010;37:170-85.

5. Borger MA, Alam A, Murphy PM, Doenst T, David TE. Chronic ischemic mitral regurgitation: repair, replace or rethink? Ann Thorac Surg. 2006;81: 1153-61.

6. Murphy MO, Rao C, Punjabi PP, Athanasiou T. In patients undergoing mitral surgery for ischaemic mitral regurgitation is it preferable to repair or to replace the mitral valve? Interact Cardiovasc Thorac Surg. 2011;12:218-28.

7. Vassileva CM, Boley T, Markwell S, Hazelrigg S. Meta-analysis of short-term and long-term survival following repair versus replacement for ischemic mitral regurgitation. Eur J Cardiothorac Surg. 2011;39:295-303.

8. Maltais S, Schaff HV, Daly RC, Suri RM, Dearani JA, Sundt TM III, et al. Mitral regurgitation surgery in patients with ischemic cardiomyopathy and ischemic mitral regurgitation: factors that influence survival. J Thorac Cardiovasc Surg. 2011;142:995-1001.

9. Chan V, Ruel M, Mesana T. Mitral valve replacement is a viable alternative to mitral valve repair for ischemic mitral regurgitation: a case-matched study. Ann Thorac Surg. 2011;92:1358-66.

10. Magne J, Girerd N, Senechal M, Mathieu P, Dagenais F, Dumesnil JG, et al. Mitral repair versus replacement for ischemic mitral regurgitation: comparison of short-term and long-term survival. Circulation. 2009;120:S104-11.

11. Gillinov AM, Wierup PN, Blackstone EH, Bishay ES, Cosgrove DM, White J, et al. Is repair preferable to replacement for ischemic mitral regurgitation? J Thorac Cardiovasc Surg. 2001;122:1125-41.

12. Grossi EA, Goldberg JD, LaPietra A, Ye X, Zakow P, Sussman M, et al. Ischemic mitral valve reconstruction and replacement: comparison of long-term survival and complications. J Thorac Cardiovasc Surg. 2001;122:1107-24.

13. Akins CW, Miller DC, Turina MI, Kouchoukos NT, Blackstone EH, Grunkemeier GL, et al. Guidelines for reporting morbidity and mortality after cardiac valvular interventions. J Thorac Cardiovasc Surg. 2008;135:732-8.

14. Gelsomino S, Lorusso R, Caciolli S, Capecchi I, Rostagno C, Chioccioli M, et al. Insights on left ventricular and valvular mechanisms of recurrent ischemic mitral regurgitation after restrictive annuloplasty and coronary artery bypass grafting. J Thorac Cardiovasc Surg. 2008;136:507-18.

15. Zoghbi WA, Enriquez-Sarano M, Foster E, Grayburn PA, Kraft CD, Levine RA, et al. American Society of Echocardiography recommendations for evaluation of the severity of native valvular regurgitation with two-dimensional and Doppler echocardiography. J Am Soc Echocardiogr. 2003;16:777-802.

16. Members of the Chamber Quantification Writing Group, Lang RM, Bierig M, Devereux RB, et al. Recommendations for chamber quantification: a report from the American Society of Echocardiography's Guidelines and Standards Committee and the Chamber Quantification Writing Group, developed in conjunction with the European Association of Echocardiography, a branch of the European Society of Cardiology. J Am Soc Echocardiogr. 2005; 18:1440-63.

17. Austin PC. A tutorial case study in propensity score analysis: an application to estimating the effect of in-hospital smoking cessation counseling on mortality. Multivariate Behav Res. 2011;46:119-51.

18. Austin PC. Optimal caliper widths for propensity-score matching when estimating differences in means and differences in proportions in observational studies. Pharm Stat. 2011;10:150-61.

19. Cohn LH, Rizzo RJ, Adams DH, Cooper GS, Sullivan TE, Collins JJ. The effect of pathophysiology in the surgical treatment of ischemic mitral regurgitation: operative and late risks repair versus replacement. Eur J Cardiothorac Surg. 1995;9: 568-74. 
20. ten Brinke EA, Klautz RJ, Tulner SA, Verwey HF, Bax JJ, Delgado V, et al. Clinical and functional effects of restrictive mitral annuloplasty at mid-term follow up in heart failure patients. Ann Thorac Surg. 2010;90:1913-21.

21. Hung J, Papakostas L, Tahta SA, Hardy BG, Bollen BA, Duran CM, et al. Mechanism of recurrent ischemic mitral regurgitation. Circulation. 2004;110: II85-90.

22. Calafiore AM, Di Mauro M, Gallina S, Di Gianmarco G, Iacò AL, Teodori G, et al. Mitral valve surgery for chronic ischemica mitral regurgitation. Ann Thorac Surg. 2004;77:1989-97.

23. De Bonis M, Lapenna E, Verzini A, La Canna G, Grimaldi A, Torracca L, et al. Recurrence of mitral regurgitation parallels the absence of left ventricular remodeling after mitral repair in advanced dilated cardiomyopathy. Ann Thorac Surg. 2008;85:932-9.

24. Athanasiou T, Chow A, Rao C, Aziz O, Siannis F, Ali A, et al. Preservation of the mitral valve apparatus: evidence synthesis and critical reappraisal of surgical techniques. Eur J Cardiothorac Surg. 2008;33:391-401.

25. Perrault LP, Moskowitz AJ, Kron IL, Acker MA, Miller MA, Horvath KA, et al. Optimal surgical management of severe ischemic mitral regurgitation: to repair or to replace? J Thorac Cardiovasc Surg. 2012;143:1396-403.

\section{Discussion}

Dr Irving Kron (Charlottesville, Va). I must say I have a conflict of interest in that I am a primary investigator for the Cardiothoracic Surgical Network.

I would like to congratulate the authors on an outstanding paper. They have been accurate and clear and discussed the issues with such an analysis. They have done a database study of $>1000$ patients with CIMR. This is a retrospective study with propensity matching. The findings were interesting. Patients with MVR had a 3\% mortality versus $5 \%$ for MVP, and this was not significant. The 8-year survival was exactly the same. Based on these findings, it would seem that MVR is certainly a reasonable strategy.

There are, however, difficulties with this assessment. First and foremost, this is a retrospective study with little standardization of the procedures or choice of repair versus replacement. In the replacement group, the majority of patients did not have chordal sparing of both leaflets. The majority of patients were followed less than 5 years, so prosthetic failure cannot truly be analyzed at this point. But bottom line, this suffers all the issues of any retrospective study, although this is an excellent attempt to give us an answer to this clinical problem.

The Network study is a randomized study, and we have just closed enrollment of 250 patients randomized to mitral repair vs replacement. Of course, the issue is as the authors stated: Is repair less risky versus the issues of later recurrence? So I believe the randomized trial may give us an answer to this, but certainly not the long-term follow-up at this point. I have two questions for the authors.

The first is, could they predict which patients who had repairs were likely to recur? They have a great data set. The second question is whether, with longer follow-up, will there be more reoperations for the prosthetic replacement group? Thank you very much for an excellent effort.

Dr Parolari. Thank you so much, Dr Kron, for your questions. For the first one, up to now the core lab is still investigating the problem of prediction of mitral valve recurrence. The problem is that this is a retrospective study, and the earliest cases date back to about 15 years, and also the echocardiographic variables that were collected in earlier cases were different than the ones that were collected in later ones. We know that this is one of the next tasks to be addressed, but up to now I don't have any data about that.

The second question is the problem of reoperation on bioprosthetic valves. I think the problem raised in our paper is the following one. We have selected somehow lower risk patients because we excluded reoperations, we excluded emergency cases, and we had high survival rates. I mean both in the replacement and in the repaired valve groups, the estimated survival at 8 years was around $80 \%$. If so, many patients with a bioprosthetic valve survive in the long term, and we know that bioprosthetic valves may have problems at longer follow-up times. This is going to be an issue. And probably we will see that, in the future, when longer follow-up times are available, although up until now, the difference between a patient who got a mechanical prosthesis and a patient who got a bioprosthesis in terms of reoperation was not statistically different.

Dr John D. Puskas (Atlanta, Ga). Thank you for your presentation. You have really tackled a difficult problem and applied a careful analysis of a large data set to that problem. One of the challenges that Dr Kron mentioned is that this is a retrospective study. One of the points of entry of bias into a retrospective study is patient exclusion. You chose to exclude patients who left the hospital and left the operating room with residual mitral regurgitation after mitral repair for CIMR. If your study is to guide decision making by surgeons, it seems to me that the decision is made well prior to hospital discharge; the decision is made, in fact, prior to or in the operating room whether to repair or replace the valve. Why did you exclude patients who had an imperfect repair from your analysis?

Dr Parolari. First of all, we excluded patients who had $>1+$ grade mitral regurgitation at follow-up. We decided to do that because it is our practice, at least in past years, to leave no more than $1+\mathrm{MR}$, and we don't leave $2+\mathrm{MR}$ or higher degrees if there is not a good reason. Another reason why we excluded patients with $>1+$ MR is because many people are discussing the problem concerning what group of patients to be compared. Some people say-and even Dr Bolling, whom I see here, was already saying that - that, in case of CIMR, you don't have 2 groups to compare, but you have 3 . The first one is a good repair, the second is a bad repair, and the third one is MVR. So we wanted to exclude the worst repairs and just to compare only the good repairs with MVR.

Dr Steven F. Bolling (Ann Arbor, Mich). A very nice study on a very vexing problem. You really have 2 groups. You have replacement and repair, and you must have 2 subgroups in your repair group. Seventy-five percent of those patients got a good repair and $25 \%$ got a bad repair with residual and recurrent MR, and yet you blend them together to analyze their survival. That can't be valid. The $75 \%$ who had a good repair probably do better, and the $25 \%$ bad repair dragged the survival average back down to the same as replacement.

I have 2 questions for you. Reflecting on what Dr Kron said, in the group of bad repairs, the $25 \%$, did you identify anything that led to a bad repair? And also, did you do analysis on these patients in terms of their initial LV size, which may be a far more important indicator of their long-term outcome as opposed to ejection fraction?

Thank you. Very nice study. 
Dr Parolari. Thank you for your question. First of all, concerning LV diameters and LV dimensions, in the beginning, the LV end systolic diameter mean was $56 \mathrm{~mm}$ in the repair group and $59 \mathrm{~mm}$ in the replacement group. However, the end diastolic volume was $117 \mathrm{~mL}$ in both groups. We do not have, up to now, predictors concerning the results of repairs. It was difficult for us to decide what was a good repair and a bad repair at the beginning because we were working on retrospective data and we just could go back to the chart. So it is very difficult for us to answer the question.

Dr Robert A. Dion (Genk, Belgium). I would like to insist on the fact that when one attacks such a population one has to qualify it. I mean, there is for sure a group of patients with preoperative LV dimensions and LV volumes who are doing much better with 1 of the 2 solutions. For instance, I believe that if the preoperative LV end diastolic diameter much exceeds $65 \mathrm{~mm}$, the patient is probably better off even with a replacement.

What I miss in your paper is that you should not only classify the patients according to mitral valve repair versus replacement, but qualify them according to the preoperative dimensions, preoperative volumes, postoperative incidence, and the rate reverse remodeling, because these parameters will deeply influence the outcome, maybe even more than the type of procedure.

And finally let us say that you replace the valve with a bioprosthesis and the patient benefits from a LV remodeling and survives long enough for the bioprosthesis to degenerate. This patient now faces a reoperation for a re-replacement of the mitral valve, which might have been anticipated by a careful analysis of the preoperative parameters, don't you think?

Dr Parolari. Concerning the problem of the dimensions, Dr Dion, I thank you for this question, the problem is that these data were collected over a 15 -year period of time and they were retrospective. And concerning also the possible predictors of that, it is very difficult for me to answer this question, but it will be answered probably much better from the Cardiothoracic Surgery Network in the currently running trial.

About bioprostheses, this is a big problem. We are still investigating that. Hopefully next year, probably Dr Roberto Lorusso, who is the principal investigator, will have more answers about that that we don't have now. Thank you.

APPENDIX 1. Preoperative demographic, clinical, and echocardiographic data in the unmatched population

\begin{tabular}{|c|c|c|c|}
\hline Variable & Repair $(\mathbf{n}=708)$ & Replacement $(\mathbf{n}=\mathbf{2 9 8})$ & Standardized difference \\
\hline Age, y; mean \pm SD & $65.8 \pm 9.1$ & $70.3 \pm 8.0$ & 1.538 \\
\hline Sex, male/female; n $(\%)$ & $537 / 171(75.8 / 24.2)$ & $204 / 94(68.4 / 31.6)$ & 0.155 \\
\hline $\mathrm{BSA}, \mathrm{kg} / \mathrm{m}^{2} ;$ mean $\pm \mathrm{SD}$ & $1.79 \pm 0.2$ & $1.75 \pm 0.2$ & 0.089 \\
\hline NYHA functional class; mean \pm SD & $2.5 \pm 1.1$ & $2.9 \pm 1.2$ & 0.373 \\
\hline EuroSCORE; mean \pm SD & $13.5 \pm 3.4$ & $13.9 \pm 3.2$ & 0.220 \\
\hline Family history, $\mathrm{n}(\%)$ & $413(58.3)$ & $169(60.0)$ & 0.642 \\
\hline Hypertension, n (\%) & $354(50.0)$ & $119(39.9)$ & 0.007 \\
\hline Diabetes, n (\%) & $243(34.3)$ & $122(40.9)$ & 0.213 \\
\hline COPD, n (\%) & $147(20.7)$ & $75(25.1)$ & 0.128 \\
\hline $\mathrm{CRD}, \mathrm{n}(\%)$ & $183(25.8)$ & $92(30.7)$ & 0.108 \\
\hline CVD, n $(\%)$ & $65(9.1)$ & $92(11.7)$ & 0.403 \\
\hline PVD, n (\%) & $26(3.6)$ & $20(6.7)$ & 0.008 \\
\hline $\mathrm{AF}, \mathrm{n}(\%)$ & $77(10.8)$ & $40(13.3)$ & 0.384 \\
\hline Pulmonary hypertension, $\mathrm{n}(\%)$ & $70(9.8)$ & $33(11.0)$ & 0.644 \\
\hline History of CHF, n (\%) & $371(52.4)$ & $179(60.0)$ & 0.433 \\
\hline IABP, n (\%) & $254(35.8)$ & $119(39.9)$ & 0.469 \\
\hline \multicolumn{4}{|l|}{ MI localization, $\mathrm{n}(\%)$} \\
\hline Anterior & $159(22.5)$ & $72(24.1)$ & 0.744 \\
\hline Lateral & $197(27.8)$ & $72(24.1)$ & 0.090 \\
\hline Inferoposterior & $352(49.7)$ & $154(51.6)$ & 0.819 \\
\hline Left main CAD & $154(21.7)$ & $66(22.1)$ & 0.901 \\
\hline \multicolumn{4}{|l|}{ Echocardiographic data, mean $\pm \mathrm{SD}$} \\
\hline LVEF, \% & $35.8 \pm 2.9$ & $36.6 \pm 3.8$ & 0.437 \\
\hline $\mathrm{EDD}, \mathrm{mm}$ & $56.0 \pm 8.7$ & $59.0 \pm 6.0$ & 1.106 \\
\hline $\mathrm{ESD}, \mathrm{mm}$ & $42.5 \pm 7.7$ & $44.2 \pm 6.3$ & 0.642 \\
\hline $\mathrm{EDV}, \mathrm{mL}$ & $175 \pm 29.7$ & $173 \pm 28.8$ & 0.369 \\
\hline $\mathrm{ESV}, \mathrm{mL}$ & $112 \pm 19.2$ & $109 \pm 20.1$ & 0.677 \\
\hline MR, grade & $2.8 \pm 0.5$ & $3.0 \pm 0.5$ & 0.282 \\
\hline
\end{tabular}

$S D$, Standard deviation; $B S A$, body surface area; $N Y H A$, New York Heart Association; COPD, chronic obstructive pulmonary disease; $C R D$, chronic renal disease; $C V D$, cerebral vascular disease; $P V D$, peripheral vascular disease; $A F$, atrial fibrillation; $C H F$, congestive heart failure; $I A B P$, intra-aortic balloon pump; $M I$, myocardial infarction; $C A D$, coronary artery disease; $L V E F$, left ventricular ejection fraction; $E D D$, end diastolic diameter; $E S D$, end systolic diameter; $E D V$, end diastolic volume; $E S V$, end systolic volume; $M R$, mitral regurgitation. 
APPENDIX 2. Operative data in the unmatched population

\begin{tabular}{|c|c|c|c|}
\hline Variable & $\begin{array}{c}\text { Repair } \\
(\mathbf{n}=708)\end{array}$ & $\begin{array}{l}\text { Replacement } \\
(\mathbf{n}=\mathbf{2 9 8})\end{array}$ & $\begin{array}{c}\text { Standardized } \\
\text { difference }\end{array}$ \\
\hline $\mathrm{CPB}$ time, min; mean $\pm \mathrm{SD}$ & $158 \pm 36$ & $138 \pm 29$ & 3.356 \\
\hline ACC time, min; mean $\pm \mathrm{SD}$ & $117 \pm 39$ & $101 \pm 30$ & 2.105 \\
\hline \multicolumn{4}{|l|}{ Distal anastomoses, n (\%) } \\
\hline 1 & $133(18.8)$ & $45(15.1)$ & \\
\hline $2-4$ & $560(69.1)$ & $242(81.2)$ & \\
\hline$>4$ & $15(2.1)$ & $11(3.7)$ & \\
\hline $\begin{array}{l}\text { No. of anastomoses/patient, } \\
\text { mean } \pm \text { SD }\end{array}$ & $2.7 \pm 0.4$ & $2.9 \pm 0.5$ & 0.298 \\
\hline $\begin{array}{l}\text { Failed mitral valve repair, } \\
\mathrm{n}(\%)\end{array}$ & - & $11(3.6)$ & - \\
\hline $\begin{array}{l}\text { No. of arterial grafts/ } \\
\text { patient, mean } \pm \text { SD }\end{array}$ & $1.4 \pm 0.2$ & $1.6 \pm 0.4$ & 0.365 \\
\hline \multicolumn{4}{|l|}{ Ring size, n (\%) } \\
\hline $26 \mathrm{~mm}$ & $185(26.1)$ & - & - \\
\hline $28 \mathrm{~mm}$ & $362(51.2)$ & - & - \\
\hline $30 \mathrm{~mm}$ & 99 (13.9) & - & - \\
\hline $32 \mathrm{~mm}$ & $34(4.8)$ & - & - \\
\hline $34 \mathrm{~mm}$ & $15(2.2)$ & - & - \\
\hline $36 \mathrm{~mm}$ & $13(1.8)$ & - & - \\
\hline Mean \pm SD & $28.2 \pm 2.1$ & - & - \\
\hline Median (IQR) & $28(26-28)$ & - & - \\
\hline \multicolumn{4}{|l|}{ Ring type, n (\%) } \\
\hline $\begin{array}{l}\text { Carpentier Edwards } \\
\text { Classic }\end{array}$ & $76(10.7)$ & - & - \\
\hline $\begin{array}{l}\text { Carpentier Edwards } \\
\text { Physio }\end{array}$ & 278 (39.9) & - & - \\
\hline $\begin{array}{l}\text { Carpentier Edwards } \\
\text { Physio II }\end{array}$ & $193(27.3)$ & - & - \\
\hline $\begin{array}{l}\text { Carpentier } \\
\text { McCarthyETlogix }\end{array}$ & $27(3.8)$ & - & - \\
\hline Geoform & $13(1.8)$ & - & - \\
\hline St Jude Medical Seguin & $11(1.5)$ & - & - \\
\hline $\begin{array}{l}\text { St Jude Medical Rigid } \\
\text { Saddle }\end{array}$ & $5(0.7)$ & - & - \\
\hline Sorin Memo 3D & $105(14.8)$ & - & - \\
\hline \multicolumn{4}{|l|}{ Prosthesis size, $\mathrm{n}(\%)$} \\
\hline $25 \mathrm{~mm}$ & - & $40(13.4)$ & - \\
\hline $27 \mathrm{~mm}$ & - & $102(34.2)$ & - \\
\hline $29 \mathrm{~mm}$ & - & 115 (38.6) & - \\
\hline $31 \mathrm{~mm}$ & - & $29(9.7)$ & - \\
\hline $33 \mathrm{~mm}$ & - & $12(4.1)$ & - \\
\hline Mean \pm SD & - & $28.1 \pm 1.9$ & - \\
\hline Median (IQR) & - & $29(27-29)$ & - \\
\hline \multicolumn{4}{|l|}{ Prosthesis type, n (\%) } \\
\hline \multicolumn{4}{|l|}{ Biologic } \\
\hline Carpentier Edwards & - & $92(54.2)$ & - \\
\hline $\begin{array}{l}\text { Carpentier Edwards } \\
\text { MAGNA }\end{array}$ & - & $7(4.1)$ & - \\
\hline Sorin Mitroflow & - & $21(12.4)$ & - \\
\hline Medtronic Hancock II & - & $8(4.7)$ & - \\
\hline Medtronic Mosaic & - & $30(17.6)$ & - \\
\hline St Jude Medical Epic & - & $10(5.8)$ & - \\
\hline Labcor & - & $1(0.6)$ & - \\
\hline Moore & - & $1(0.6)$ & - \\
\hline
\end{tabular}

APPENDIX 2. Continued

\begin{tabular}{|c|c|c|c|}
\hline Variable & $\begin{array}{c}\text { Repair } \\
(n=708)\end{array}$ & $\begin{array}{l}\text { Replacement } \\
(\mathbf{n}=\mathbf{2 9 8})\end{array}$ & $\begin{array}{c}\text { Standardized } \\
\text { difference }\end{array}$ \\
\hline \multicolumn{4}{|l|}{ Mechanical } \\
\hline St Jude Medical & - & $16(12.6)$ & - \\
\hline Sorin Bicarbon & - & $12(9.4)$ & - \\
\hline Carbomedics & - & $43(33.6)$ & - \\
\hline ATS & - & $1(0.7)$ & - \\
\hline On-X & - & $56(43.7)$ & - \\
\hline \multicolumn{4}{|c|}{$\begin{array}{l}\text { Mitral leaflets preservation, } \\
\text { n }(\%)\end{array}$} \\
\hline None & - & $47(36.7)$ & - \\
\hline Posterior & - & $29(22.6)$ & - \\
\hline Both & - & $52(40.7)$ & - \\
\hline
\end{tabular}

